DOI: http://dx.doi.org/10.18764/2358-4319.v11n2p34-59

\title{
Reflexões acerca do movimento 'Escola sem Partido' inspiradas pelas teorias de Paulo Freire e Pierre Bourdieu
}

Jovanka Mariana de Genova Ferreira ${ }^{1}$

Gisele Pereira de Souza²

\section{RESUMO}

Ao analisar as teorias de Pierre Bourdieu e Paulo Freire sobre educação, bem como a posição acadêmica e política dos autores sobre o tema, o artigo pretende refletir sobre projeto 'Escola sem Partido' e sua implicação em relação à prática dentro da sala de aula. Tal movimento que, nos últimos tempos, ganhou destaque no cenário brasileiro é contra o que chama de doutrinação política e ideológica dos alunos por parte dos professores e a usurpação dos direitos dos pais na educação moral e religiosa de seus filhos. Constatou-se que no cenário brasileiro atual existe uma iniciativa de diminuir a força da análise crítica dentro das escolas. A própria natureza do 'Escola sem Partido' traz essa premissa, pois a intenção de desmerecer a posição política do professor junto aos seus alunos demonstra que o propósito seja desqualificar a iniciativa de incentivar uma consciência crítica, o que, de múltiplas formas discutidas no presente estudo, colabora para que a relação oprimido e opressor prospere.

Palavras-chave: Educação. Autonomia do Indivíduo. Escola sem Partido

\section{Reflections about 'Escola sem Partido' inspired by the theories of Paulo Freire and Pierre Bourdieu}

Analyzing the theories of Pierre Bourdieu and Paulo Freire on education, as well as the academic and political position of the authors on the theme, the article intends to reflect on the project "Escola Sem Partido" and its implication in relation to the practice within the classroom. This movement, which recently gained prominence in the Brazilian scenario,

1 Mestranda do Programa de pós Graduação: Educação, Arte e História da Cultura da Universidade Presbiteriana Mackenzie. Graduada em Filosofia e em Administração. E-mail: jovanka_mariana@hotmail.com

2 Mestre pelo Programa de Pós-Graduação em Ciência da Informação pela ECA/USP. Graduada em Biblioteconomia. Coordenadora do Centro de Memória e Referência da Aberje Associação Brasileira de Comunicação Empresarial. E-mail: giseleps@gmail.com. 
is against what it calls the political and ideological indoctrination of students by teachers and the usurpation of the rights of parents in the moral and religious education of their children. It was found that in the current Brazilian scenario there is an initiative to reduce the force of critical analysis within schools. The very nature of the "Escola Sem Partido" has this premise, since the intention to discredit the teacher's political position with his students demonstrates that the purpose is to disqualify the initiative to encourage a critical conscience. What, in many ways is discussed in the present study, contributes to the oppressed and oppressive relationship to thrive.

Keywords: Education. Autonomy of the Individual. Escola sem Partido.

\section{Reflexiones sobre la 'Escola sem Partido' inspirada por las teorías de Paulo Freire y Pierre Bourdieu}

\section{RESUMEN}

Al analizar las teorías de Pierre Bourdieu y Paulo Freire sobre educación, así como la posición académica y política de los autores sobre el tema, el artículo pretende reflexionar sobre proyecto "Escola sem Partido" y su implicación con relación a la práctica dentro del aula. Tal movimiento, que en los últimos tiempos ganó destaque en el escenario brasileño está en contra lo que llama de adoctrinamiento político e ideológico de los alumnos por parte de los profesores y la usurpación de los derechos de los padres en la educación moral y religiosa de sus hijos. Se constató que en el escenario brasileño actual existe una iniciativa de disminuir la fuerza del análisis crítico dentro de las escuelas. La propia naturaleza de la "Escola sem Partido" aporta esa premisa, pues la intención de desmerecer la posición política del profesor junto a sus alumnos demuestra que el propósito sea descalificar la iniciativa de incentivar una conciencia crítica. Lo que, de múltiples formas discutidas en el presente estudio, colabora para que la relación oprimido y opresor prospere.

Palabras clave: La educación. Autonomía del individuo. Escola sem Partido.

\section{Introdução}

Pierre Bourdieu e Paulo Freire deixaram um legado teórico que desperta muitas reflexões ligadas à área de Educação. Os estudos feitos 
pelos autores podem justificar e auxiliar no entendimento do cenário atual da educação brasileira e contribuir para que novas perspectivas e pesquisas sejam feitas a partir de suas ideias.

Freire defende uma pedagogia de sonhos possíveis (2014a). A visão freireana resgata um aprofundamento nos sentimentos e a busca por soluções para a profissão de educador e para o campo da formação em escolas. Essa força idealizadora é um estímulo e inspiração para os que atuam na área educacional.

Em contrapartida a essa proposta - humana e até mesmo em alguns casos utópica de Paulo Freire, encontramos a teoria crítica de Pierre Bourdieu, que dedicou muito da sua trajetória para esclarecer o papel da escola e a sua forma de disseminação e perpetuação do poder das classes dominantes.

Entre a produção de Pierre Bourdieu, buscamos reflexões sobre o papel da herança cultural familiar e como isso afeta diretamente o desempenho escolar do aluno. O papel da escola na reprodução e legitimação da desigualdade social pode ser observado na reflexão:

\begin{abstract}
Mas não é suficiente enunciar o fato da desigualdade diante da escola, é necessário descrever os mecanismos objetivos que determinam a eliminação contínua das crianças desfavorecidas. Parece, com efeito, que a explicação sociológica pode esclarecer completamente as diferenças de êxito que se atribuem, mais frequentemente, às diferenças de dons. A ação do privilégio cultural só é percebida, na maior parte das vezes, sob suas formas mais grosseiras, isto é, como recomendações ou relações, ajuda no trabalho escolar ou ensino suplementar, informação sobre o sistema de ensino e as perspectivas profissionais. Na realidade, cada família transmite a seus filhos, mais por vias diretas, um certo capital cultural e um certo ethos, sistema de valores implícitos e profundamente interiorizados, que contribui para definir, entre coisas, as atitudes face ao capital cultural e à instituição escolar (BOURDIEU, 1966 apud NOGUEIRA; CATANI, 2015, p. 46).
\end{abstract}

Paulo Freire, considerado o patrono da educação brasileira, traz uma reflexão para uma pedagogia capaz de construir uma nova realidade para a classe oprimida (2014a, 2014b, 2015 e 2016). Seu objetivo é que essa classe social, a partir do conhecimento formal da escola, possa ter a oportunidade de mudar sua situação socioeconômica. Com o amparo da educação, esse indivíduo terá consciência crítica do 
seu papel social e da sua autonomia, podendo assim deixar a classe de oprimidos e construir uma nova ordem social, mais humana, justa e igualitária.

A educação, por ser um ato político, fomenta as relações entre educando e educador, que são alvo de uma disputa maior da sociedade, corroborando com a premissa de Paulo Freire, de que não existe uma educação neutra, sem direcionamento político.

Em oposição às visões dos autores Bourdieu e Freire, existe um projeto, o 'Escola sem Partido', que representa pais e estudantes da sociedade civil, contrários ao que eles próprios denominam de "doutrinação política e ideológica dos alunos por parte dos professores" e a "usurpação dos direitos dos pais na educação moral e religiosa de seus filhos".

O movimento 'Escola sem Partido' existe desde 2004, mas apenas em 2015 começou a ser conhecido na grande mídia, graças à aceitação de projetos de lei baseados na ideologia do grupo, nas Câmaras Municipais, Estaduais e no próprio Congresso Nacional.

Um exemplo da força do movimento está em Alagoas, onde uma lei inspirada no movimento foi criada e o caso foi parar no Supremo Federal (STF) e na Advocacia Geral da União (AGU), que considerou o processo inconstitucional, justamente porque infringe o artigo 2016 da Constituição, que garante a pluralidade de ideias no ambiente de ensino (MORENO; TENENTE; FAJARDO, 2016).

Pierre Bourdieu: uma trajétoria acadêmica para o mundo cultural e escolar

O francês Pierre Bourdieu considerado por muitos teóricos como o mais importante sociólogo da segunda metade do século XX, devido a suas pesquisas etnográficas e estudos empíricos sobre os processos de diferenciação e reprodução social e sobre a dura realidade dos trabalhadores.

Bourdieu desenvolveu uma reflexão sobre o termo cultura e a sua expansão a partir do grupo dominante. Não existe indicador que afirme que uma cultura é melhor que a outra, mas o que difere é o valor dado para uma determinada cultura ao legitimar outra cultura. A cultura do grupo dominante se estabelece a partir dos valores simbólicos que são atribuídos às suas características. 
A ideia de associar o conceito 'cultura' ao termo econômico 'capital' foi definido pelo sociólogo como uma metáfora para falar das vantagens culturais e sociais de famílias e indivíduos, que lhes permitem possuir um nível socioeconômico mais elevado comparado aos que não possuem esse acesso cultural.

O autor, nesse processo, cunha os conceitos de 'capital cultural' e 'capital social' para somar ao conceito de capital econômico, que até então era a única forma de compreensão da integração e ligação entre o nível socioeconômico e os bons resultados educacionais. Bourdieu ultrapassa a visão meramente econômica e reúne nos termos 'capital cultural' e'capital social' os argumentos essenciais para explicação do sucesso ou não de um indivíduo em sua vida escolar.

Uma das contribuições mais ricas e inquietantes da teoria de Bourdieu é o termo 'capital cultural', que nasce a partir das primeiras observações etnográficas do autor e reflete em toda a sua trajetória intelectual com destaque para o uso no campo da educação. Esse conteúdo revela os mecanismos responsáveis pelas desigualdades do desempenho escolar, com forte influência no fato de estudantes oriundos de diferentes classes sociais fazerem parte de uma mesma sala de aula.

Essa contribuição do autor faz emergir questões pertinentes às relações entre saber e poder dentro da sala de aula. A reflexão nos leva a entender como a escola na perspectiva de Bourdieu, comentada por Nogueira e Catani (2015, p.9), permite e solidifica a diferença entre as classes sociais, como descrito no trecho abaixo:

Os educandos provenientes de famílias desprovidas
de capital cultural apresentarão uma relação com as
obras de cultura veiculadas pela escola que tende a
ser interessada, laboriosa, tensa, esforçada, enquanto
para os indivíduos originários de meios culturalmen-
te privilegiados essa relação está marcada pelo dile-
tantismo, desenvoltura, elegância, facilidade verbal
"natural". Ocorre que, ao avaliar o desempenho dos
alunos, a escola leva em conta, sobretudo- conscien-
te ou inconscientemente - esse modo de aquisição
(e uso) do saber ou, em outras palavras, essa relação
com o saber.

O conceito de capital social refere-se ao conjunto de capital econômico e cultural que um indivíduo pode acumular durante a sua vida. O capital social não pode ser independente do econômico e do cultural, 
pois existe uma relação entre eles e um fator multiplicador sobre o capital social. Por isso, o interesse de mantê-lo homogêneo, ou seja, dentro da classe social dominante e com o objetivo de concentrar esse capital e seus benefícios dentro do grupo beneficiado. Isso aumenta seu prestígio e o torna cada vez mais restrito.

O capital social é o recurso ligado a um grupo de relacionamento que se reconhece como par e que possui vínculos em um determinado grupo. Esses indivíduos são ligados por propriedades comuns, por isso o volume do capital social de um indivíduo depende das relações que pode ou consegue mobilizar e do volume do capital (econômico, cultural ou simbólico) que é posse exclusiva de cada um daqueles a que está ligado.

Esse processo do capital social é legitimado em ocasiões e em lugares a que apenas membros de uma mesma classe social têm acesso. No caso das classes sociais mais altas, isso acontece em cruzeiros, escolas seletas, cerimônias culturais - lugares que reúnem pessoas com qualidades e bens comuns. São pessoas que frequentam lugares que permitem que a homogeneidade de estilos os faça permanecer unidos para preservar o capital social, cultural e o econômico.

\section{Questões sobre a Escola à Luz de Bourdieu}

Bourdieu, no artigo "A escola conservadora: as desigualdades frente à escola e à cultura" (BOURDIEU, 1966 apud NOGUEIRA; CATANI, 2015, p. 45), desvenda as condições sociais e culturais que criaram o mito do 'dom' dentro da escola e reflete sobre os mecanismos de ensino resultados da transmissão familiar, que se apresenta dentro do ambiente escolar como uma forma de desigualdade escolar.

A escola é essencial para a teoria de 'capital cultural' desenvolvida por Bourdieu, pois é nesse espaço dedicado ao saber que o 'capital cultural' começa a ser mensurado como lucro ou prejuízo, e onde se determina a seleção dos melhores alunos. É no espaço físico da escola que serão determinados os diferentes processos para acentuarem as diferenças entre as crianças de diferentes classes sociais.

O mérito e a importância dos estudos de Bourdieu destacam-se quando ele consegue demonstrar que a escola não é um lugar democrático, onde a oportunidade está disponível para todos. A escola proporciona uma exclusão branda, silenciosa, despercebida, má e determinan- 
te para a formação dos alunos. A simulação de igualdade que a escola proporciona assegura a proximidade dos excluídos no interior das suas estruturas, de onde se consegue melhor manipulação do que se oferece a eles e, dessa forma, reservar e perpetuar os lugares mais desvalorizados para esses alunos dentro da sociedade.

Bourdieu considera que

$$
\begin{aligned}
& \text { É provavelmente por um efeito de inércia cultural } \\
& \text { que continuamos tomando o sistema escolar como } \\
& \text { um fator de mobilidade social, segundo a ideologia } \\
& \text { da "escola libertadora", quando, ao contrário, tudo } \\
& \text { tende a mostrar que ele é um dos fatores mais efica- } \\
& \text { zes de conservação social, pois fornece a aparência } \\
& \text { de legitimidade às desigualdades sociais, e sanciona } \\
& \text { a herança cultural e o dom social tratado como dom } \\
& \text { natural (BOURDIEU, } 1966 \text { apud NOGUEIRA; CATANI } \\
& \text { 2015, p. 45). }
\end{aligned}
$$

O conceito do 'capital cultural' de Bourdieu pode ser usado para explicar a desigualdade de desempenho escolar de crianças de diferentes classes sociais. É algo para relacionar e justificar o que se chama de 'sucesso escolar', que são os benefícios específicos que crianças de diferentes classes sociais podem obter na escola.

Como afirma Bourdieu, tal postura significa uma ruptura com os pressupostos inerentes, tanto à visão comum que considera o sucesso ou fracasso escolar, como efeito das 'aptidões' naturais, quanto às teorias do 'capital humano' (BOURDIEU, 1966 apud NOGUEIRA; CATANI, 2015, p. 9).

Diante do fato da desigualdade existente dentro do ambiente escolar, o principal destaque fica para mecanismos que alimentam essas diferenças - que também são sutis e, em muitos momentos, são mascarados pelo que é chamado de 'dom'. $\mathrm{O}$ dom atribui ao aluno exclusivamente a capacidade de ir bem ou não na escola.

Bourdieu afirma que é necessário se entender a ação do privilégio cultural que é transmitido pela família para seus filhos. $O$ ethos é um sistema de valores implícitos e profundamente interiorizados, determinante para definir as atitudes frente ao capital cultural e à escola.

A influência do capital cultural se deixa apreender sob a forma de relação, muitas vezes constatada, entre o nível cultural global da família e o êxito escolar da criança (BOURDIEU, 1966 apud NOGUEIRA; CATANI, 2015, p. 46). Também temos que destacar que, da mesma maneira, os jovens de setores sociais superiores podem se distinguir por conta 
da classe social em que estão inseridos, os jovens de classes sociais inferiores, que chegam a níveis de escolaridade altos, também pertencem a núcleos familiares que são diferentes da média da sua classe social, tanto por seu nível cultural e pelo seu tamanho - Bourdieu afirma que famílias menores têm mais condições de investir no estudo dos filhos comparados a famílias com muitos membros.

Além do conhecimento que o aluno recebe dos seus pais, ele também herda certo refinamento nos seus gostos e escolhas que, dentro da sala de aula pode ser atribuído, como já dito, ao dom individual do aluno. Diante disso, essas atitudes imponderáveis e intangíveis aumentam as diferenças entre as crianças e seus rendimentos. $O$ professor acentua esse processo de diferenciação, pois alimenta uma postura de privilégios, elogios e incentivos, que perpetua esse comportamento, já que a estrutura escolar protege essas vantagens em detração à transmissão aberta dos privilégios. Os autores Nogueira e Cantani destacam:

Com efeito, para que sejam favorecidos os mais favorecidos e desfavorecidos os mais desfavorecidos, é necessário e suficiente que a escola ignore, no âmbito dos conteúdos do ensino que transmite, dos métodos e técnicas de transmissão e dos critérios de avaliação, as desigualdades culturais entre as crianças das diferentes classes sociais. Em outras palavras, tratando todos os educandos, por mais desiguais que sejam eles de fato, como iguais em direitos e deveres, o sistema escolar é levado a dar sua sanção às desigualdades iniciais diante da cultura (BOURDIEU, 1996 apud NOGUEIRA; CATANI, 2015, p. 59).

Toda a estrutura criada para se ter uma sensação de igualdade dentro da escola é um cenário desenvolvido para esconder e dificultar o entendimento do tamanho da desigualdade real do ensino e da cultura transmitida e, que é exigida como forma de reconhecimento e mérito.

A escola tem a nobre função de transmitir ao maior número de pessoas possível o conhecimento através de um aprendizado. Pela troca de atitudes e aptidões, seria a única capaz de reduzir (ao menos parcialmente) a desigualdade dentro da sociedade. O currículo adotado nas escolas em geral é escolhido para atender a cultura dominante. As crian- 
ças que estão inseridas nesse contexto são mais uma vez beneficiadas, já que se trata de um conteúdo de fácil assimilação devido à proximidade do assunto com as experiências que suas famílias as proporcionam.

As crianças que não possuem esse acesso são obrigadas a se adaptarem a um conteúdo do qual não possuem alguma referência, pois o que recebem de suas famílias não as ajudam na sua vida escolar, a não ser o que Bourdieu chama de 'boa vontade cultural vazia'. Os estudantes oriundos de uma classe média são forçados a tudo esperar e a tudo receber da escola e são sujeitos, ainda por cima, a ser repreendidos pela escola por suas condutas por demais 'escolares' (BOURDIEU, 1996 apud NOGUEIRA; CATANI, 2015).

No processo de elitização do currículo escolar, em geral, o professor tem uma afinidade estrutural, uma inclinação com os valores dos grupos privilegiados do ponto de vista cultural (BOURDIEU, 1996 apud NOGUEIRA; CATANI, 2015). Isso explica a tendência a desvalorizar o conteúdo e as qualidades dos alunos que não possuem esse conhecimento. O professor acaba sendo um produto da aristocracia, no que tange ao seu conteúdo - o que autor explica como sendo um sentimento de dever por seu sucesso acadêmico e social, em:

Produtos de um sistema voltado para a transmissão de uma cultura aristocrática em seu conteúdo e espírito, os educadores inclinam-se a desposar os seus valores, com mais ardor, talvez porque lhe devem o sucesso universitário e social, além do mais, como não integrariam, mesmo e sobretudo sem que disso tenha consciência, os valores de seu meio de origem ou de pertencimento às suas maneiras de julgar e de ensinar? Assim, no ensino superior, os estudantes originários das classes populares e médias serão julgados segundo a escala de valores das classes privilegiadas, que numerosos educadores devem à sua origem social e que assumem de bom grado, sobretudo se o seu pertencimento à elite data de sua ascensão ao magistério (BOURDIEU, 1996 apud NOGUEIRA; CATANI, 2015, p. 60).

Para Bourdieu, conhecer melhor as condições de produção do conhecimento é a premissa para a produção de um conhecimento melhor 
(BURAWOY, 2011, p. 26). O autor defende que a única forma de amenizar tal diferença é a escola ter uma postura declarada e não silenciosa e despercebida de como o conhecimento é concebido e distribuído entre os alunos.

\section{A transmissão do Capital Cultural}

O ambiente familiar é determinante para a transmissão do capital cultural. Isso porque a família é influenciadora das possibilidades do sucesso ou não da criança na sua trajetória escolar.

A família que desenvolve uma educação consciente, dentro de uma atmosfera propícia para o acompanhamento das atividades de sala de aula, atenta às tarefas para casa, estimulante para conversas sobre o cotidiano e que reflita e faça análises críticas dos fatos do cotidiano, cria vínculos essenciais para a criança. Para Bourdieu (1996 apud NOGUEIRA; CATANI, 2015, p. 52), "as mesmas condições objetivas que definem as atitudes dos pais e dominam as escolhas importantes da carreira escolar regem também a atitude das crianças diante dessas mesmas escolhas e, consequentemente, toda sua atitude com relação à escola".

Por isso, o destaque que Bourdieu faz para as famílias de baixa renda que promovem um ambiente de desenvolvimento cultural e que privilegiam o exercício intelectual e reflexivo de suas crianças, preparando-as para desenvolver competências que diretamente elas não possuem, mas que lhe darão condições para que isso seja alcançado, como afirma o autor:

Da mesma forma que os jovens das camadas superiores se distinguem por diferenças que podem estar ligadas a diferenças de condição social, também os filhos das classes populares que chegam até $o$ ensino superior parecem pertencer a famílias que diferem da média de sua categoria tanto por seu nível cultural global como por seu tamanho: ... A presença no círculo familiar de pelo menos um parente que tenha feito ou esteja fazendo curso superior testemunha que essas famílias apresentam uma situação cultural original, quer tenham sido afetadas por uma mobilidade descendente ou tenham uma atitude frente à ascensão que as distinguem do conjunto das famílias de sua catego- 
ria (BOURDIEU, 1996 apud NOGUEIRA; CATANI, 2015, p. 48).

A família de baixa renda pode acreditar no potencial individual da criança, a incentivar a não se intimidar com as diferenças econômicas e culturais que irão existir com às outras crianças de classes sociais altas. Essas diferenças serão mais acentuadas no início do processo educacional, mas, ao longo da vida escolar, essa diferença pode ser anulada e, essa criança se tornar tão capaz quanto qualquer outro que tenha um capital cultural mais elevado.

Esse tipo de família, como afirma o autor, também tem um diferencial na sua formação, pois estimula o contato com o capital cultural e o faz ser um aliado para a sua ascensão social e econômica.

O autor também destaca o movimento ao contrário. Nem todos os indivíduos que possuem fácil acesso ao capital cultural, por descenderem de classes dominantes, desenvolvem habilidades para se apropriarem desse capital. Muitos indivíduos simplesmente não têm disposição e competência para colocar o poder do seu capital cultural adquirido na família em prática, de forma a possuir um patrimônio muito consistente e rico. Alguns escolhem não expandir, socializar e praticá-lo.

Paulo Freire: a trajetória para a construção de uma pedagogia da autonomia

Contemporâneo a Bourdieu, o pernambucano Paulo Freire se tornou leitura obrigatória para os educadores preocupados com as condições existenciais dos seus alunos, para aqueles que fazem da oportunidade de lecionar um salto para a transformação e mudança do ser humano. Sua teoria está focada em uma educação orientada para a liberdade: seus estudos são direcionados às classes sociais mais baixas, para que essas por meio de uma educação inclusiva sejam capazes de se instrumentalizarem e se prepararem intelectualmente, a fim de alterarem a sua realidade e agirem contra a opressão das classes dominantes e do capitalismo.

Para entender a obra e a teoria proposta por Paulo Freire, é importante descrever a relação de contradição entre o opressor e oprimido. Esse vínculo é algo fundamental para o entendimento e compreensão da teoria freireana. 
No prefácio à $60^{\circ}$ edição brasileira da 'Pedagogia do Oprimido', Celso de Rui Beisiegel, traz uma contribuição para que se identifique que a teoria de Paulo Freire é reflexo direto do seu trabalho em campo e do público a que faz referência:

Nas "Primeiras palavras" de Pedagogia do Oprimido, o autor declara que as afirmações feitas no livro não eram "fruto de devaneios intelectuais" tampouco resultavam "apenas de leituras, por mais importantes que tenham sido". Estariam sempre ancoradas em situações concretas, expressando reações "de proletários, camponeses ou urbanos, e de homens de classe média", que vinha observando, direta ou indiretamente, em seu trabalho educativo (FREIRE, 2016, p 17).

No primeiro capítulo do livro Pedagogia do Oprimido (2016), Freire relata a relação antagônica e oposta entre opressores e oprimidos, que resulta em uma ordem social opressora e desumana. Humanização e desumanização são possibilidades que existem para todos os homens. Porém, a humanização seria algo que se pudesse chamar de vocação dos homens, já que a desumanização é uma distorção da vocação do ser mais do homem (FREIRE, 2016, p. 62). Freire afirma que essa distorção é possível na história, mas não na vocação histórica, porque caso assumíssemos como verdade que a desumanização é uma vocação histórica dos homens, nada mais teríamos que fazer, a não ser adotar uma atitude cínica ou de total desespero. (FREIRE, 2016, p. 63).

Essa luta entre opressor e oprimido para Paulo Freire só faz sentido se na busca pela humanidade o oprimido se liberte a si e aos opressores, liberta-se de uma realidade opressora que os desumaniza. Freire reforça que

A violência dos opressores, que os faz também desumanizados, não instaura outra vocação - a do ser menos. Como distorção do ser mais, o ser menos leva os oprimidos, cedo ou tarde, a lutar contra quem os fez menos. E esta luta somente tem sentido quando os oprimidos, ao buscarem recuperar sua humanidade, que é uma forma de criá-la, não se sentem idealistamente opressores, sem se tornam, de fato, opressores dos opressores, mas restauradores da humanidade em ambos (FREIRE, 2016, p. 63). 
A preocupação do autor em existir uma pedagogia capaz de colaborar nesse processo de crescimento da consciência do oprimido faz com que ele construa a Pedagogia do Oprimido, que tem como objetivo ser "aquela que tem de ser forjada com ele e não para ele, enquanto homens ou povos, na luta incessante de recuperação de sua humanidade" (FREIRE, 2016, p. 65).

\title{
Educar é um Ato Político
}

Freire entende que a educação está intrinsecamente ligada à politica. A educação não pode ser dissociada da política, já que se reconhece que a própria educação é um ato político. $O$ educador se dedica para que a política da educação seja reconhecida e entendida como tal, pois a emancipação da classe trabalhadora é o ponto fundamental para o desenvolvimento da sociedade e isso permeia as políticas públicas vigentes, já que não existe uma educação neutra. Moacir Gadotti (2014, p.15), no prefácio de Educação e Mudança, relata

\begin{abstract}
Depois de Paulo Freire ninguém mais pode ignorar que a educação é sempre um ato político. Aqueles que tentam argumentar em contrário, afirmando que o educador não pode "fazer política", estão defendendo uma certa política, a política da despolitização. Pelo contrário, se a educação, notadamente a brasileira, sempre ignorou a política, a política nunca ignorou a educação. Ela sempre foi política. Ela sempre esteve a serviço das classes dominantes. Este é um princípio de que parte Paulo Freire, princípio subjacente a cada página que aqui escreveu.
\end{abstract}

O legado freireano está direcionado à disseminação do conhecimento aos oprimidos de uma sociedade e ao desenvolvimento de espaços para exercício de sua autonomia. Como afirma o autor, em sociedades cuja dinâmica estrutural conduz à dominação de consciência, "a pedagogia dominante é a pedagogia das classes dominantes" (FREIRE, 2016, p. 33).

Uma educação como prática de liberdade irá permitir que a classe dominada crie condições de refletir e descobrir-se sujeito da sua própria história. Essa é a oportunidade de desenvolver uma consciência crítica que revele o real papel do indivíduo dentro da estrutura social e as aberturas que lhe são oferecidas para seu desenvolvimento e libertação a partir do seu desenvolvimento, por isso o posicionamento claro 
da defesa de se entender a educação como política já que essa interfere diretamente nas oportunidades de crescimento social do indivíduo.

\section{Papel do Educador para Paulo Freire}

A argumentação contrária de Paulo Freire para esse modelo bancário é que exista uma prática mais humana, uma educação que respeita e aceita a história do educando e faz do educador um mediador sensível à realidade da classe de aula. $O$ educador deve propiciar um espaço possível para o desenvolvimento de uma prática educacional que oriente seus alunos para o engajamento da luta por sua libertação.

Paulo Freire diz que um educador humanista, revolucionário, não irá esperar que seus alunos sozinhos percebam a contradição da educação bancária. O educador deverá participar desse processo de conscientização quando "Sua ação, identificando-se, desde logo, com a dos educandos, deve orientar-se no sentido da humanização de ambos." (FREIRE, 2016, p. 110).

Na proposta de educação freireana, o educador deve ter na sua essência um potencial progressista, que irá criar formas de entender e encarar a opressão de uma maneira que possibilite e facilite o caminho para transformação da realidade de indivíduo. É necessário que exista educação para que o sujeito consiga superar as suas imperfeições, Freire diz que o homem sempre estará em constante busca por aprimoramento, porque este é inacabado e "A educação é uma resposta da finitude da infinitude" (FREIRE, 2014b, p. 34).

Outro ponto importante a ser destacado por Freire é que o educador deve entender que aqueles que ensinam não estão diante de ignorantes, mas que o fato de eles serem alunos não exclui o conhecimento que esses possuem, que é um saber relativo ao do educador, nesse modelo adotado por Freire. Freire entendia que "A prática educacional não é o único caminho à transformação social necessária à conquista dos direitos humanos, contudo, sem ela, jamais haverá transformação social" e que a "educação consegue dar às pessoas maior clareza para "lerem o mundo", e essa clareza abre a possibilidade de intervenção política. É essa clareza que lançará um desafio ao fatalismo neoliberal" (FREIRE, 2014a, p. 50).

Nessa concepção educacional, educadores e educandos precisam estar integrados por uma pauta comum que é construída a partir 
da igualdade e respeito, que fará com que essa relação seja baseada no diálogo capaz de desenvolver um processo de vias iguais, ou seja, os educadores têm o papel de ensinar, mas também de aprender.

Ensinar, para Paulo Freire, exige disponibilidade para o diálogo, o que irá permitir ao professor que ele conheça, experimente e vivencie algo que está no outro, em um processo de troca. $O$ educador já não seria o que apenas educa, "mas o que, enquanto educa, é educado, em diálogo com o educando que, ao ser educado, também educa" (FREIRE, 2016, p. 23). Para tanto, precisa existir abertura, disponibilidade e humildade para apreciar a oportunidade para testemunhar essa experiência, como explica o autor:

A experiência da abertura como experiência fundante do ser inacabado que terminou por ser inacabado. Seria impossível saber-se inacabado e não se abrir ao mundo e aos outros à procura de explicação, de respostas a múltiplas perguntas, o fechamento ao mundo e aos outros se torna transgressão ao impulso natural da incompletude (FREIRE, 2016, p. 133).

Caso a rigidez da posição do professor seja mantida, o professor será sempre o que sabe enquanto seus alunos serão sempre os que não sabem (FREIRE, 2016, p.105). O professor será o ator principal e os alunos passivamente devem aceitar e isso não é uma relação, é apenas um monólogo que é a negação do homem, definido por Paulo Freire como:

O monólogo, enquanto isolamento, é a negação do homem; é fechamento da consciência, uma vez que consciência é abertura. Na solidão, uma consciência, que é consciência do mundo, adentra-se em si, adentrando-se mais em seu mundo, que, reflexivamente, faz-se mais lúcida mediação da imediatez intersubjetiva das consciências. A solidão - não o isolamento - só se mantém enquanto renova e revigora as condições do diálogo (FREIRE, 2016, p. 44).

Estabelecer uma relação profissional e carinhosa é o desafio do educador com a sua sala de aula. Adotar uma postura criativa e curiosa que provoque nos alunos a vontade de assumir seu próprio ato de conhecer, irá romper com as antigas práticas que não defendem o protagonismo dos alunos e promovem uma rigidez no ato de ensinar (FREIRE, 2015, p. 12).

O educador precisa estar atento às práticas de desumanização, para que os espaços da sala de aula e da escola não permitam o mal 
estar das diferenças e não estimule a dependência ao modelo adotado pela maioria. Para isso, os educadores precisam estar preparados para o exercício da autorreflexão crítica e colaborar para o exercício da crítica das causas reais da degradação humana e do discurso pregado pelas classes dominantes de uma educação que eduque para apenas aceitar teorias fatalistas (FREIRE, 2015, p.13).

\section{Pedagogia dos Sonhos Possíveis}

A prática educativa em Paulo Freire é inspiradora para todos os envolvidos no processo de educação, pois se mostra compreensiva com as diferenças e exala um sentimento de amor ao próximo. A educação que evidencia a alteridade e as trocas entre os indivíduos envolvidos coloca o educador como um mediador desse sentimento. $O$ autor provoca os educadores, ao dizer que quem não é capaz de amar os seres inacabados não pode educar (FREIRE, 2014b, p. 36).

O termo amor é usado por Freire com frequência nas suas obras. Para o educador, o amor é uma tarefa do sujeito e tem o outro como sujeito de seu amor. $\mathrm{O}$ amor implica uma luta contra o egoísmo e um educador que acredite em uma prática de troca, respeito e compreensão encontra em Paulo Freire uma verdadeira inspiração para suas ações no dia a dia.

A proposta freireana defende a escola como um espaço privilegiado para o pensar. Porém, Freire também afirma que a educação tem que ultrapassar os muros da escola, que não é o único lugar e exclusiva responsável pelas transformações que são necessárias à sociedade. A educação está dentro da comunidade, no momento que acontece a inserção do indivíduo, nas suas experiências cotidianas, no seu conhecimento, que é transmitido dentro do núcleo familiar. Paulo Freire valoriza a experiência cotidiana, o conhecimento individual como fonte da transformação, pois é resultado direto da vida e da realidade do povo.

A escola deve ser um local de aprendizagem e de geração de conhecimento, compartilhada com um grupo. A escola não pode ser um lugar de assistencialismo; deve formar pessoas atuantes que não aceitam serem espectadores da sua própria vida. A educação deve acompanhar esse desenvolvimento e incentivar esse engajamento, para que se mude a realidade e se acredite nos sonhos. 
A educação será responsável em formar as consciências para que construam suas trajetórias de forma justa e autônoma. O empoderamento de uma classe social passa pela liberdade da dominação e pelo engajamento político dessa população ao lutar para que a sua cultura seja reconhecida e aceita.

\begin{abstract}
A questão do empoderamento de classe social envolve como a classe trabalhadora, através de suas próprias experiências, de sua própria construção da cultura, se engaja para obter pode político. Isso faz do "empoderamento" muito mais do que um acontecimento, um evento, individual ou psicológico. Ele aponta para um processo político das classes dominadas que buscam sua própria liberdade da dominação, um longo processo histórico no qual a educação é apenas uma das suas faces (FREIRE, 2014a, p. 75).
\end{abstract}

Nesse processo, a educação é uma das etapas, já que a mobilização interna desse grupo é essencial para que esse movimento aconteça. Paulo Freire afirma que quanto mais o povo dominado se mobiliza dentro de sua cultura, mais ele se une, cresce e sonha (FREIRE, 2014a, p. 75).

O processo de reconhecimento, aceitação e entendimento dos aspectos que compõem a cultura e sua história está ligado diretamente ao processo de libertação da dominação da cultura dominante.

Para os educadores, Paulo Freire deixa o desafio de intervir na realidade e manter a esperança, como a responsabilidade de criar meios de compreensão de realidades políticas e históricas para propiciar a mudança e descreve o desafio futuro, ao afirmar que "Nossa luta de hoje não significa que necessariamente conquistaremos mudanças, mas sem que haja essa luta, hoje, talvez as gerações futuras tenham de lutar muito mais. A história não termina em nós: ela segue adiante" (FREIRE, 2014a, p. 56).

\title{
Movimento “Escola sem Partido"
}

Em 2016, o Senado lançou uma enquete pública para que a sociedade pudesse votar no Projeto de Lei 193/2016, de autoria do senador Magno Malta (PR-ES). Se esse projeto de lei for aprovado, o conteúdo fará parte das diretrizes e bases da educação nacional. O conteúdo para esse novo projeto de lei foi baseado em um movimento social chamado 'Escola sem Partido'. 
O movimento 'Escola sem Partido' - 'ESP' - foi criado em 2004 e representa pais e professores. No site do ESP, descreve-se a preocupação "com o grau de contaminação político-ideológica das escolas brasileiras" e, afirma que "um exército organizado de militantes travestidos de professores prevalece-se da liberdade de cátedra e da cortina de segredo das salas de aula para impingir-lhes a sua própria visão de mundo" (ESCOLA SEM PARTIDO, s.d.a).

O movimento ganhou força nos últimos meses graças à aceitação de projetos de leis baseados na ideologia do grupo, nas Câmaras Municipais, Estaduais e no próprio Congresso Nacional. O projeto 'ESP' almeja que as suas ideias se tornem realidades nas escolas brasileiras a partir das seguintes premissas:

Os projetos de lei do "Escola sem Partido" pretendem especificar os limites da atuação dos professores, impedindo que eles promovam suas crenças particulares em sala de aula, incitem estudantes a participarem de protestos e denigram os alunos que pensem de forma distinta. Além disso, o projeto dá o direito dos pais de escolherem como será o ensino de religiões distintas das suas ("direito dos pais dos alunos a que seus filhos recebam a educação religiosa e moral que esteja de acordo com as suas próprias convicções"). Aos professores, também cabe garantir que os estudantes ou terceiros cumpram as regras acima durante suas aulas (MORENO; TENENTE; FAJARDO, 2016).

O programa representado por Miguel Nagib em uma entrevista cedida ao portal G1 declara que a liberdade de expressão do professor não deve existir dentro da sala de aula, porque, caso contrário, isso "equivaleria a reconhecer-lhe o direito de obrigar seus alunos a ouvi-lo falar, opinar e pregar sobre qualquer assunto", o que abriria espaço para que os professores usassem o tempo de sala de aula para falar sobre qualquer assunto, mesmo que ele não seja relacionado à matéria. "Se o professor desfrutasse de liberdade de expressão em sala de aula o nosso projeto seria inconstitucional. Em compensação, como eu disse, não haveria ensino." (MORENO; TENENTE; FAJARDO, 2016).

Miguel Nagib afirma que mesmo que os alunos não sejam "foIhas em branco", eles formam a "clientela da educação básica" e "são indivíduos vulneráveis, do ponto de vista intelectual e emocional". Além disso, segundo ele, "o grau de vulnerabilidade varia de indivíduo para 
indivíduo, segundo a idade e a personalidade de cada um" (MORENO; TENENTE; FAJARDO, 2016).

Muitos professores e especialistas em educação criticam fortemente o programa e afirmam que nada na sociedade é isento de ideologia e, que o'Escola Sem Partido', na verdade, é uma proposta carregada de conservadorismo, autoritarismo e fundamentalismo cristão, como afirma Daniel Cara, em entrevista ao Portal EBC:

Além de não assumir sua mensagem conservadora, camuflada em suposto pluralismo, o 'Escola Sem Partido' quer evitar um pensamento crítico. Quer uma escola medíocre. Afirma uma ideologia pautada em um fundamentalismo cristão evitado até pelo Papa Francisco, diante das possibilidades de um papado que sucedeu o ultraconservador Bento XVI", afirma Daniel Cara, coordenador-geral da Campanha Nacional pelo Direito à Educação (SANTANA, 2016).

Na mesma linha de raciocínio sobre o programa 'Escola sem Partido', a especialista em educação Andrea Ramal defende a seguinte posição:

Andrea Ramal, especialista em educação e colunista do G1, afirma que a preocupação por trás do projeto de lei é legítima, mas que a aplicação prática pode levar a "situações absurdas", como "famílias processando escola e professor porque este mencionou determinado pensador, ou porque não deu o mesmo tempo de aula sobre o pensador 'concorrente'"' (MORENO; TENENTE; FAJARDO, 2016).

O movimento 'ESP' disponibiliza para alunos e pais que queiram advertir o professor, um modelo de notificação, que pode ser usado quando esses quiserem se prevenir contra "o abuso da liberdade de ensinar" e notificá-lo extrajudicialmente, para que ele se abstenha de adotar certas condutas em sala de aula. Esse documento é chamado de'Modelo de Notificação Extrajudicial: arma das famílias contra a doutrinação nas escolas'.

\section{Pierre Bourdieu e Paulo Freire contrapostos à proposta do movimento 'Escola sem Partido'}

Para iniciar essa reflexão, faz-se necessária a definição do que é política. Política é atividade humana por meio da qual se estabelecem as 
relações entre o Estado e a sociedade. O centro das ações políticas está nas relações entre governantes e governados ou, em uma sociedade de classes, nas relações que se verificam entre as classes dominantes e as dominadas (MONTEIRO, 2006, p. 109). Bobbio, no Dicionário de Política, completa essa definição da seguinte forma:

I. O SIGNIFICADO CLÁSSICO E MODERNO DE POLÍTICA. - Derivado do adjetivo originado de pólis (politikós), que significa tudo o que se refere à cidade e, consequentemente, o que é urbano, civil, público, e até mesmo sociável e social, o termo Política se expandiu graças à influência da grande obra de Aristóteles, intitulada Política, que deve ser considerada como o primeiro tratado sobre a natureza, funções e divisão do Estado, e sobre as várias formas de Governo, com a significação mais comum de arte ou ciência do Governo, isto é, de reflexão, não importa se com intenções meramente descritivas ou também normativas, dois aspectos dificilmente discrimináveis, sobre as coisas da cidade. Ocorreu assim desde a origem uma transposição de significado, do conjunto das coisas qualificadas de um certo modo pelo adjetivo "político", para a forma de saber mais ou menos organizado sobre esse mesmo conjunto de coisas: uma transposição não diversa daquela que deu origem a termos como física, estética, ética e, por último, cibernética (BOBBIO, 1998, p.954).

Diante dessas definições, é perceptível que a política faz parte das ações sociais e, que de uma forma consciente ou não todos os indivíduos estão envolvidos nesse processo. A política está intrinsicamente ligada a todas as relações e ações de uma sociedade, como afirma Bobbio, a política pode ser entendida como práxis humana e lida diretamente com o poder. $\mathrm{O}$ autor afirma que

O conceito de Política, entendida como forma de atividade ou de práxis humana, está estreitamente ligado ao de poder. Este tem sido tradicionalmente definido como "consistente nos meios adequados à obtenção de qualquer vantagem" (Hobbes) ou, analogamente, como "conjunto dos meios que permitem alcançar os efeitos desejados" (Russell). Sendo um destes meios, além do domínio da natureza, o domínio sobre os outros homens, o poder é definido por vezes como uma relação entre dois sujeitos, dos quais um impõe ao outro a própria vontade e lhe determi- 
na, malgrado seu, o comportamento. Mas, como o domínio sobre os homens não é geralmente um fim em si mesmo, mas um meio para obter"qualquer vantagem" ou, mais exatamente, "os efeitos desejados", como acontece com o domínio da natureza, a definição do poder como tipo de relação entre sujeitos tem de ser POLÍTICA 955 completada com a definição do poder como posse dos meios (entre os quais se contam como principais o domínio sobre os outros e sobre a natureza) que permitem alcançar justamente uma "vantagem qualquer" ou os "efeitos desejados". O poder político pertence à categoria do poder do homem sobre outro homem, não à do poder do homem sobre a natureza. Esta relação de poder é expressa de mil maneiras, onde se reconhecem fórmulas típicas da linguagem política: como relação entre governantes e governados, entre soberano e súditos, entre Estado e cidadãos, entre autoridade e obediência, etc. (BOBBIO, 1998, p.955).

Nesse processo de análise do projeto 'Escola Sem Partido', o primeiro item a ser avaliado é justamente o caráter politico do projeto. Como está na definição apresentada por Bobbio, política também pode ser entendida como um "conjunto dos meios que permitem alcançar os efeitos desejados". Dessa forma, todas as ações envolvidas e os meios para que se consiga atingir os alunos e pais do projeto 'Escola sem Partido', podem ser considerados como ações políticas.

Destaca-se esse dado justamente por se perceber na narrativa utilizada pelo representante do projeto e no conteúdo do site a intenção de manter as iniciativas do 'Escola sem Partido' como algo apartidário e sem propósitos políticos, o que corrobora com todos os propósitos defendidos pelo projeto. Porém, isso não exclui o próprio projeto ‘Escola sem Partido' de ser um agente político.

A defesa para que exista uma postura neutra dos professores nas salas de aula é apresentada pelo projeto da seguinte maneira:

A doutrinação política e ideológica em sala de aula ofende a liberdade de consciência do estudante; afronta o princípio da neutralidade política e ideológica do Estado; e ameaça o próprio regime democrático, na medida em que instrumentaliza o sistema de ensino com o objetivo de desequilibrar o jogo político em favor de um dos competidores (ESCOLA SEM PARTIDO, s.d.b) 
Paulo Freire dedicou parte da sua carreira acadêmica ao entendimento de que educação é uma ato politico e que os professores precisam se posicionar politicamente. $\mathrm{O}$ autor diz: "como educadores progressistas, uma de nossas maiores tarefas parece dizer respeito a como gerar nas pessoas sonhos políticos, anseios políticos, desejos políticos" (FREIRE, 2014a, p.5).

A Pedagogia do Oprimido é a produção intelectual de Paulo Freire, que defende a dimensão educativa, da ação dos homens empenhados na luta pela libertação de uma realidade opressora que os desumaniza (FREIRE, 2016, p. 21).

Freire acreditava que os educadores possuem um papel fundamental no desenvolvimento de uma nova realidade para a classe oprimida, posicionando-se positivamente diante de uma proposta de mudança do pensamento social e incentivando a consciência crítica e a autonomia do educando, diante do conhecimento adquirido na escola e da sociedade.

O educando deve entender seu papel dentro do processo social. Esse processo de autoconhecimento e protagonismo é algo que a escola deve estimular. E o educador será o mediador, pois ele está comprometido com a busca da humanização e incentivará o crescimento individual. Dentro desse contexto, Freire afirma que

As doutrinas neoliberais procuram limitar a educação à prática tecnológica. Atualmente, não se entende mais educação como formação, mas apenas como treinamento. Creio que devamos continuar criando formas alternativas de trabalho. Se implantada de maneira crítica, a prática educacional pode fazer uma contribuição inestimável à luta política. A prática educacional não é o único caminho à transformação social necessária à conquista dos direito humanos, contudo acredito que, sem ela, jamais haverá transformação social. A educação consegue dar às pessoas maior clareza para "lerem o mundo", e essa clareza abre a possibilidade de intervenção política. É essa clareza que lançará um desafio ao fatalismo neoliberal (FREIRE, 2014a, p.50).

A teoria de Paulo Freire é o oposto do que se defende no projeto 'Escola sem Partido', não por defender uma suposta "doutrinação", mas ao propor a interação, o diálogo, uma postura não depositária, uma valorização do aluno e da sua realidade no processo de educação, libertação mútua e empoderamento. 
O 'ESP' espera que o professor não seja educador e apenas um transmissor de conhecimento e dessa forma não contribua para que o educando tenha uma consciência critica, questione e reflita sobre qualquer ação política ou não. Isso dentro do que foi apresentado na visão de Paulo Freire é chamada de educação bancária. Contudo, o que está nas propostas do 'ESP' é uma versão piorada da educação bancária do educador pernambucano, pois o professor terá que seguir um direcionamento formal, uma lei, visto que esse é um dos objetivos do 'Escola sem Partido' - que suas ideias sejam transformadas em leis.

O francês Bourdieu acreditava que os oprimidos jamais entenderiam as origens e a condição de sua dominação e afirmava que apenas os intelectuais poderiam entender os mecanismos da sociedade, pensamento esse referendado por Burawoy em:

\footnotetext{
Apenas os intelectuais (ou pelo menos alguns deles) teriam acesso aos segredos escondidos da sociedade e da dominação sobre a qual ela jaz; ao passo que os indivíduos submetidos estariam cegos e surdos por sua submissão (BURAWOY, 2011, p. 16).
}

Diante da resistência dos oprimidos em se posicionar contra um processo de mudança, pois esses negam a sua condição de oprimido, a escola é o lugar que esse indivíduo encontrará subsídios para se entender e fortalecer seu posicionamento na sociedade. Dentro da sala de aula encontrará nos professores o conhecimento necessário para alcançar sua autonomia.

Bourdieu afirmava que o sistema escolar é eficaz na conservação social, pois fornece a aparência de legitimidade às desigualdades sociais. Esse é um ambiente perfeito para que o 'Escola sem Partido' faça crescer e prosperar sua ideologia. Porém, o francês acreditava na competência individual e nas decisões do indivíduo ao longo da sua trajetória escolar e na vida que são capazes de reverter essa situação social.

Trata-se de uma perspectiva diferente da de Paulo Freire, que acreditava na possiblidade das classes oprimidas terem bom senso para sua situação de opressão, mas que se equipara quando ambos acreditam no potencial de cada indivíduo e no papel fundamental da escola e do professor, o que também vai contra aquilo o que se propõe o movimento 'ESP'. 


\section{Considerações finais}

A teoria de Bourdieu é precisa ao identificar no 'capital cultural' uma forma de desigualdade social que interfere diretamente no'sucesso escolar'. Essa postura adotada pelo autor significa uma "ruptura com os pressupostos, tanto à visão comum que considera o sucesso ou fracasso escolar como efeito das 'aptidões' naturais, quanto às teorias do 'capital humano" (BOURDIEU, 1980 apud NOGUEIRA, CATANI, 2015, p. 9).

A análise da obra de Paulo Freire exige dedicação e raciocínio humanista muito intenso e sincero. Sem essa entrega por parte do leitor, seu raciocínio fica sem sentido, utópico e inaplicável. São necessários sentimentos de humildade e respeito, para que a prática docente seja exercida na sua completude. Todo professor precisa ter em Paulo Freire uma inspiração e um exemplo.

Constatou-se que no cenário brasileiro atual existe uma iniciativa de diminuir a força da análise crítica dentro das escolas. A própria natureza do 'Escola sem Partido' traz essa premissa, pois a intenção de desqualificar a posição crítica do professor junto aos seus alunos, demonstra que o propósito seja desqualificar a iniciativa de incentivar uma consciência crítica, o que, de alguma forma, colabora para que a relação oprimido e opressor perdure.

Seguindo a questão de desqualificação das iniciativas que ensinam o aluno a refletir e descobrir o seu papel no mundo, está a iniciativa do governo atual de retirar as disciplinas de Filosofia e Sociologia da grade curricular do Ensino Médio.

Essas duas disciplinas são responsáveis por um conteúdo fundamental para a formação reflexiva dos alunos e contribuem diretamente para o crescimento da autonomia individual, oferecendo subsídios intelectuais para o indivíduo promover mudanças de atitude, como defende Paulo Freire em seus estudos de defesa da classe oprimida.

Os impactos da exclusão dessas matérias e de toda a nova base curricular proposta pelo atual governo serão sentidos somente daqui a alguns anos, pois processos educacionais precisam de um tempo para avaliação de suas propostas e ações. Porém, podemos afirmar que a intenção de interferir na evolução social dos educandos, com a remoção das disciplinas de Sociologia e Filosofia, está muito alinhada aos objetivos das propostas do 'Escola sem Partido' (RODRIGUES, 2016). 
Outro aspecto a ser destacado é a intenção do projeto de dar um sentido negativo para os termos política e partido. Essa intenção de estabelecer um valor pejorativo para os termos exerce um papel de convencimento do projeto 'Escola sem Partido'. Esse juízo de valor somado ao cenário atual brasileiro e à rejeição atual à política e aos políticos, exemplificado nos índices de abstenção das eleições municipais brasileiras ou presidenciais norte-americanas, por exemplo, podem criar uma imagem positiva aos ideais do movimento e a manutenção das suas ações.

\section{Referências}

BOBBIO, Norberto; MATTEUCCI, Nicola; PASQUINO, Gianfranco. Dicionário de Política. 11. ed. Brasília: Editora Universidade de Brasília, 1998. Disponível em <http://www.filoczar.com.br/Dicionarios/ Dicionario_De_Politica.pdf> Acesso em: 06 nov. 2016.

BURAWOY, Michael. O marxismo encontra Bourdieu. Campinas: Editora Unicamp. 2011.

ESCOLA SEM PARTIDO. Sobre nós. s.d.a. Disponível em: <http://www. escolasempartido.org/sobre-nos-footer $>$ Acesso em: 06 de jul. 2018.

ESCOLA SEM PARTIDO. Artigos. Por uma lei contra o abuso da liberdade de ensinar. s.d.b. Disponível em: <http://escolasempartido. org/component/content/article/2-uncategorised/482-uma-lei-contrao-abuso-da-liberdade-de-ensinar> Acesso em: 06 de jul. 2018.

FREIRE, Paulo. (Org) Ana Maria Araújo Freire. Pedagogia dos sonhos possíveis. 1ed; São Paulo: Paz e Terra, 2014a.

FREIRE, Paulo. Educação e mudança. 36 ed.rev. e atual. São Paulo: Paz e Terra, 2014b.

. Pedagogia da Autonomia. 52. ed. Rio de Janeiro: Paz e Terra, 2015.

Pedagogia do oprimido. 60. ed. Rio de Janeiro: Paz e Terra, 2016.

GADOTTI, M. (Org.). Prefácio. In: FREIRE, P. Educação e Mudança. 36 ed.rev. e atual. São Paulo: Paz e Terra, 2014. 
MONTEIRO, Antonio Luiz Ribeiro. Estado e Política: breves reflexões conceituais. Revista de Geografia, Recife, v.23, n.2, p. 104-122, 2006. Disponível em: <http://www.revista.ufpe.br/revistageografia/index. php/revista/article/viewFile/73/33> Acesso em: 06 nov. 2016.

MORENO, Ana Carolina; TENENTE, Luiza; FAJARDO, Vanessa. Entenda a polêmica em torno do 'Escola sem Partido'. G1. Educação. 08 ago. 2016. Disponível em: http://g1.globo.com/educacao/noticia/entendaa-polemica-em-torno-do-escola-sem-partido.ghtml Acesso em: 20 de out. 2016.

NOGUEIRA, Maria Alice; CATANI, Afrânio. (Orgs.). Pierre Bourdieu. Escritos em Educação. Petrópolis: Vozes, 2015.

RODRIGUES, Mateus. Governo lança reforma do ensino médio; veja destaques. G1. Educação. 22.set.2016. Disponível em: < http://g1.globo. com/educacao/noticia/temer-apresenta-medida-provisoria-dareforma-do-ensino-medio-veja-destaques.ghtml> Acesso em: 15 nov. 2016.

SANTANA, Ana Elisa. Escola sem Partido: entenda o que é movimento que divide opiniões na Educação. EBC. Educação. 20 jul. 2016. Disponível em: <http://www.ebc.com.br/educacao/2016/07/o-que-e-o-escola-sem -partido> Acesso em: 20 de out. 2016.

Recebido em abril/2018

Aceito em maio/2018 